\title{
Approach to Fingertip Injuries
}

Patricia Martin-Playa, MD, Anthony Foo, MD*

\section{KEYWORDS}

- Fingertip injuries • Fingertip amputation $\bullet$ Nail bed injuries $\bullet$ Closed injuries $\bullet$ Psychosocial factors

\section{KEY POINTS}

- Fingertip injuries are common and there is a wide spectrum of presentation.

- Restoration of a stable, pain-free, and normal looking fingertip is the main goal of treatment.

- Psychosocial factors are important considerations in the formulation of a treatment plan.

\section{INTRODUCTION}

The fingertip comprises the nail complex and glabrous pulp, which are richly vascularized and innervated, built around the distal phalanx. Its dense innervation ${ }^{1}$ and disproportionally large and intricate cortical representation ${ }^{2}$ emphasize the importance of addressing psychological factors. Minor contusions can result in pain syndromes in some patients, whereas others adapt well to deformed fingertips, highlighting the nonlinear relationship between physical and psychological trauma.

\section{GOALS OF TREATMENT}

The goals of treatment of any injured fingertip should be the restoration of a stable interface for object manipulation while looking as normal as possible. At the completion of treatment, the pulp should be stable and pain free, and the nail plate geometry should permit the manipulation of small objects.

\section{PLANNING TREATMENT}

A focused history and physical examination is obtained to establish the most appropriate intervention for each patient. The characteristics of the injury determine the range of treatment, whereas psychosocial factors aid clinicians in selecting the most appropriate option. Psychosocial factors to be considered are occupation, hobbies, cultural norms, socioeconomic status, secondary motive, and clinician bias. ${ }^{3-8}$

\section{CLOSED INJURIES}

The 3 main considerations for closed fingertip injuries are the nail plate, pulp, and bone. The size of the subungual hematoma is thought to correlate with the degree of the nail matrix injury, and an arbitrary figure of $50 \%$ is considered an indication for nail avulsion and matrix repair (Fig. 1) to facilitate anatomic healing. ${ }^{9}$ An alternative approach, where nail trephination alone was performed regardless of the size of the hematoma, provided the nail plate was intact, yielded good pain relief with satisfactory nail plate regeneration. ${ }^{10}$ The presence of a tuft fracture did not adversely affect the outcome in this series, in which patients with fractures received a splint to maintain the distal interphalangeal joint in extension for comfort.

\section{OPEN INJURIES WITHOUT TISSUE LOSS}

Given the density of critical structures in the fingertip, it is prudent to exclude flexor tendon,

Disclosure Statement: The authors declare no potential conflicts of interest with respect to the research, authorship, and/or publication of this article.

Department of Hand and Reconstructive Microsurgery, National University Hospital, 1E Kent Ridge Road, Singapore 119228, Singapore

* Corresponding author.

E-mail address: tun.foo@gmail.com 


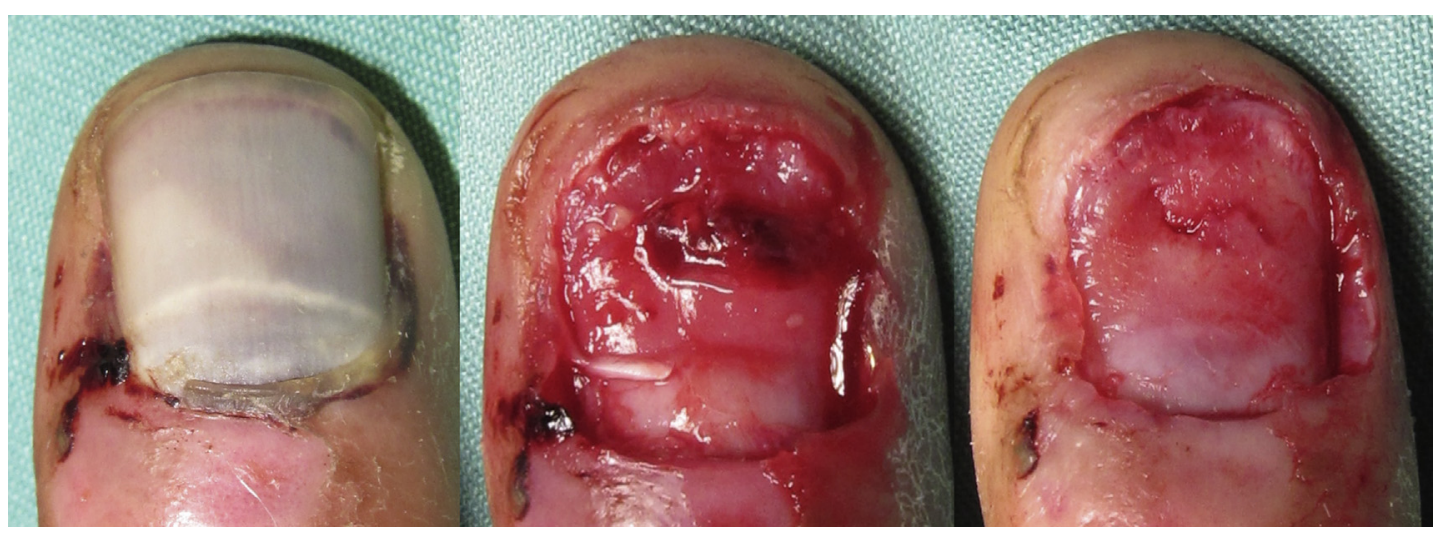

Fig. 1. A $75 \%$ hematoma with intact nail plate (left). Untidy laceration with interposed hematoma (middle). Laceration is evident after clearance of hematoma (right). Nail trephination is a viable alternative in this scenario.

digital nerve, or artery laceration in open injuries of the pulp (Fig. 2). Although distal digital nerve repair does not predict sensory recovery, ${ }^{11,12}$ it is worth documenting and repairing neurotmetic injuries in clinical practice for which medicolegal risks are high. Nail matrix injuries are typically repaired with absorbable sutures to restore contour and surface for nail regeneration. Skin glue is an effective alternative to sutures for the repair of simple or complex lacerations and suitable for children in the emergency room setting. ${ }^{13}$

\section{OPEN INJURIES WITH TISSUE LOSS Healing by Secondary Intention}

Pulp reconstruction after tissue loss receives disproportionate attention owing to the wide array of options for reconstruction, limited only by imagination. Before indulging our imagination, it is worth considering the possibility of healing through secondary intention, which can be surprisingly effective; its results may be aesthetically superior to graft or flap reconstruction, without incurring donor site morbidity. ${ }^{14}$ Common indications for secondary intention healing are wounds without exposed bare bone or tendon, and a wound size of less than $1 \mathrm{~cm}^{2}$. However, noncritical portion of exposed bone or tendon can be excised to facilitate healing. Wound vascularity rather than size is more important in considering treatment options; a small, well-vascularized wound $\left(<1 \mathrm{~cm}^{2}\right)$ would almost certainly recover in a week or two, whereas larger wounds would take a few weeks more. Graft or flap reconstruction expedites the recovery process, while incurring potential donor morbidity. The principles of

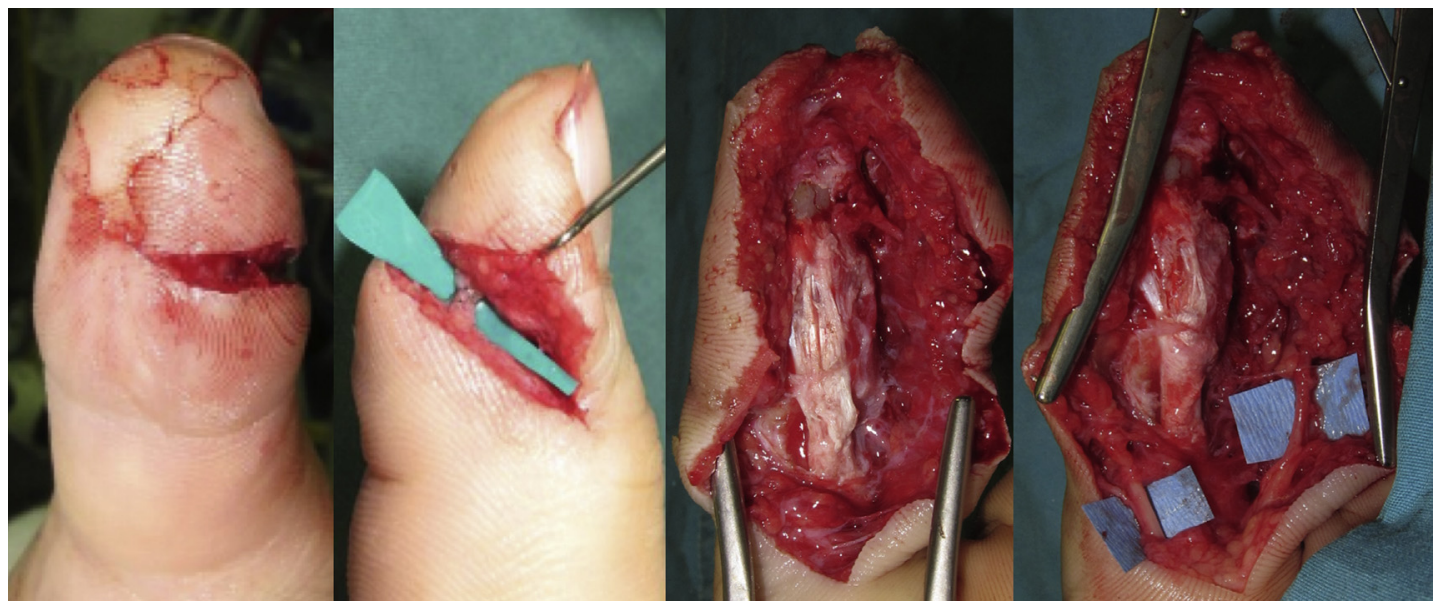

Fig. 2. Simple laceration of the thumb pulp resulted in transection of the digital nerve, which was repaired (left). Flexor tendon and digital nerves were found to be intact in a burst laceration of the pulp (right). 

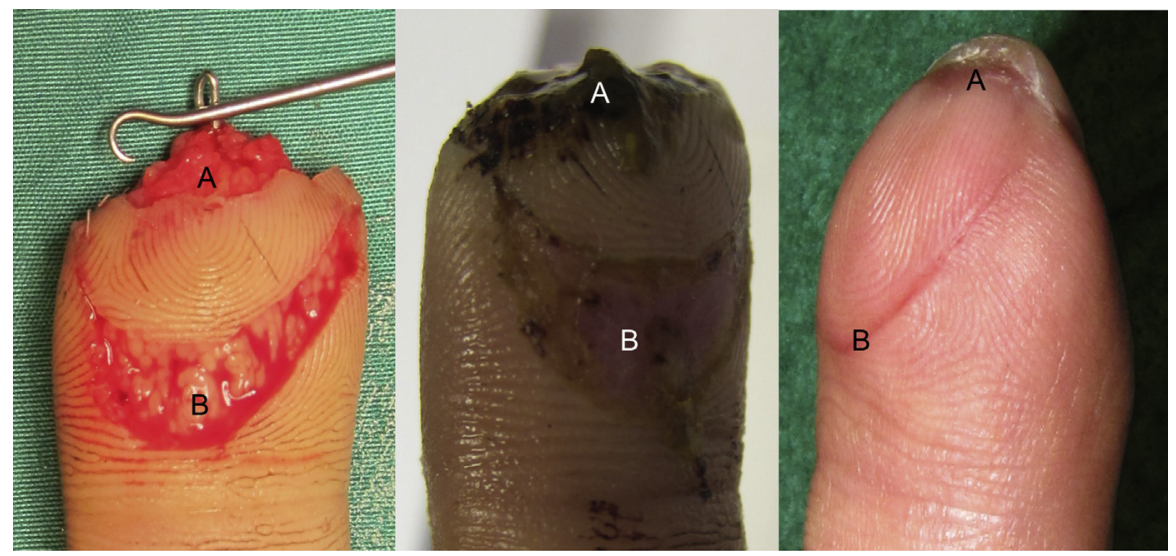

Fig. 3. Fingertip amputation treated with a modified local advancement flap (left). Residual defects $(A, B)$ were allowed to heal by secondary intention ( 2 weeks, middle) with a satisfactory outcome ( 3 months, right).

secondary intention can be applied to reduce flap requirement, for example, using a smaller flap to cover only the critical portion, whereas residual defects are allowed to heal by secondary intention (Fig. 3).

\section{Composite Graft}

The outcome of a composite graft is generally predictable in young children, ${ }^{15}$ but outcomes were less predictable in adults. ${ }^{16}$ In adults, we observed some degree of graft shrinkage and contour distortion with nail deformity (Fig. 4). As long as the patient understands the implications of the procedure, composite grafting is a good alternative with no donor morbidity.

\section{Skin Grafts}

Moynihan ${ }^{17}$ reported that the "condemnation of the use of Thiersch graft (split skin graft) has almost been unanimous," and this paradigm has been preserved and inherited by contemporary surgeons. It is worth noting that Moynihan stressed that a thin graft over a bony prominence was the cause of tenderness and sensitivity rather than the use of split thickness graft. ${ }^{18,19} \mathrm{~A}$ full-thickness skin graft (FTSG) was applied with caution over exposed bone and tendon in the mid twentieth century, but contemporary investigators have shown that a FTSG can be reliably used in the context of exposed bone or tendon. ${ }^{20}$ We use skin grafts judiciously for pulp reconstruction, and we note imperceptible differences between glabrous and nonglabrous graft in the long term, because the graft remodels according to stress to which it is exposed (Fig. 5). Donor site morbidity is prioritized over like-for-like reconstruction because there are limited donor sites for glabrous skin. The ulnar aspect of the hand has been described as a donor site, but we would avoid this area because it is often the surface on

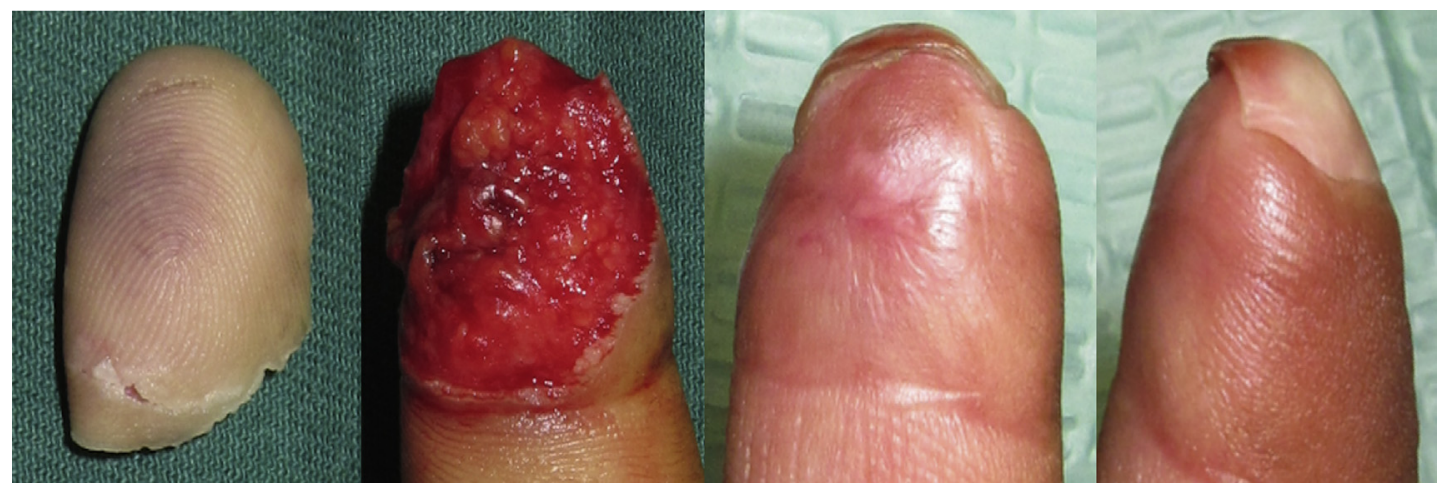

Fig. 4. Avulsion amputation of the pulp was replaced as a composite graft in an adult patient. Graft atrophy and fingertip contour and nail plate distortion observed 6 months later 


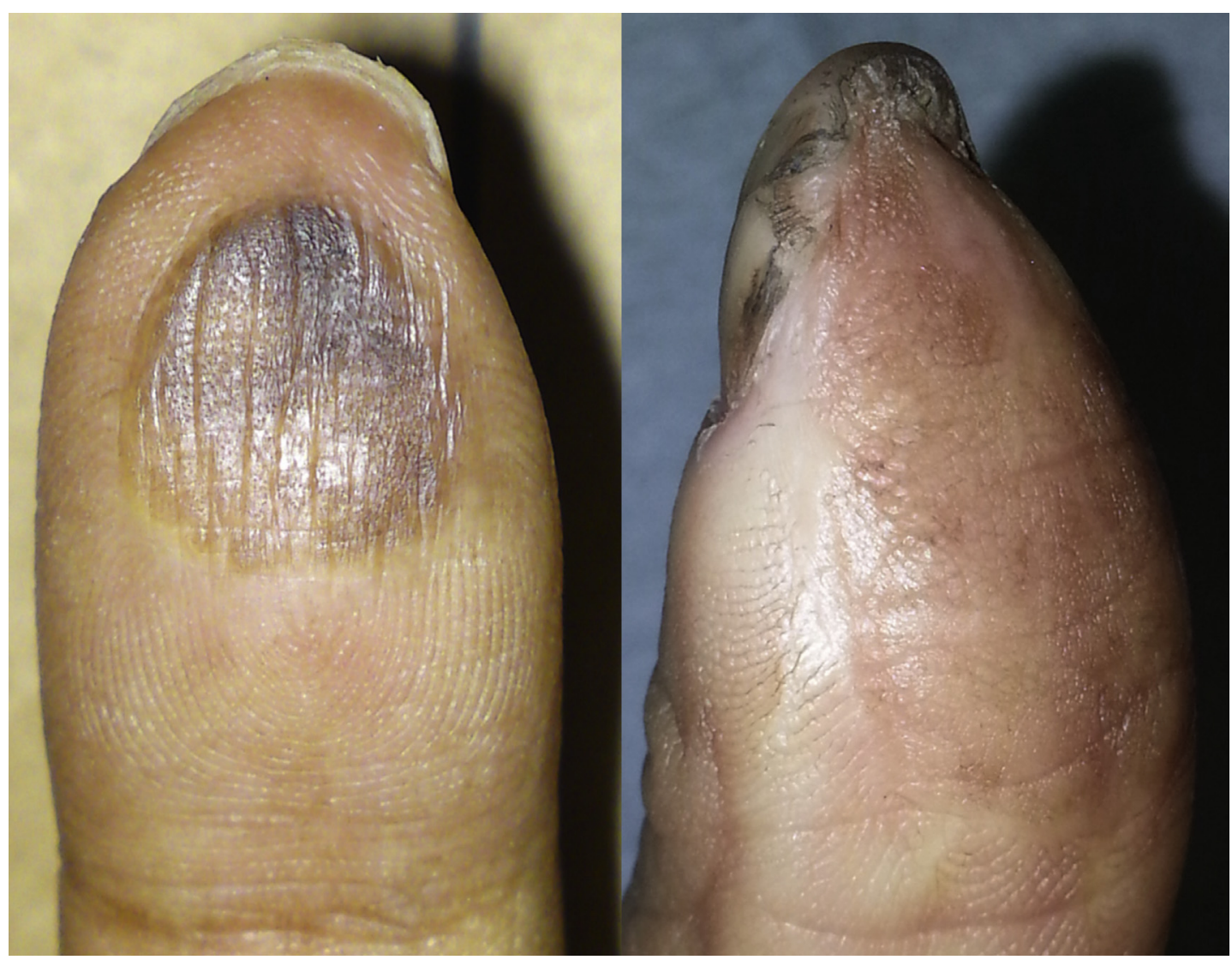

Fig. 5. Skin grafts remodel according to the stress imposed upon it. Glabrous remodeling of skin grafts noted in the long term at 3 years after split thickness skin graft (left), and 25 years after FTSG (right).

which the hand rests during activity. The palmar creases, midaxial skin, and dorsal joint creases provide FTSG that are up to $15 \mathrm{~mm}$ wide with minimal functional and cosmetic morbidity (Fig. 6)..$^{21,22}$

\section{Flap Reconstruction}

Few topics excite hand surgeons as much as a discussion of the options for fingertip reconstruction. The majority of fingertip losses are adequately treated with $\mathrm{VY}$ advancement ${ }^{23,24}$ and cross-finger flaps. ${ }^{25}$ Island flaps extend the options for further refinement of reconstructive approach, while imposing greater technical demands. Surgical techniques on numerous flaps can be found in the works by these investigators. ${ }^{26,27}$ These texts are by no means exhaustive, because new or modifications of known techniques are frequently reported in the literature.

Our flap selection process is based on the dichotomy of homodigital versus heterodigital options, followed by patient choice, and then surgeon expertise. Patients are shown a photo of the anticipated outcome of the common flaps because their perception of the beautiful normal may vary. From a surgical perspective, we encourage younger colleagues to master VY advancement and cross-finger flaps before undertaking the various forms of neurovascular or vascular island flaps. We generally avoid heterodigital flaps to limit injury to a single digit, and similarly, cross-finger flaps are avoided in older patients owing to the higher risk of finger stiffness. VY flaps, ${ }^{23,24}$ triangular, ${ }^{28}$ or step-cut ${ }^{29}$ neurovascular island flaps are our workhorses for fingertip reconstruction. Frequent contact areas such as radial aspect of index and middle fingers, and ulnar aspect of little finger are avoided as island flap donor sites to minimize scar sensitivity (Fig. 7). Dissection and mobilization of the neurovascular bundle up to the common digital artery bifurcation with or without adjacent arterial division is routinely performed to facilitate flap advancement of 15 to $20 \mathrm{~mm}$. Proximal interphalangeal joint flexion is avoided, and postprocedure proximal interphalangeal joint mobilization is emphasized to minimize joint stiffness. 


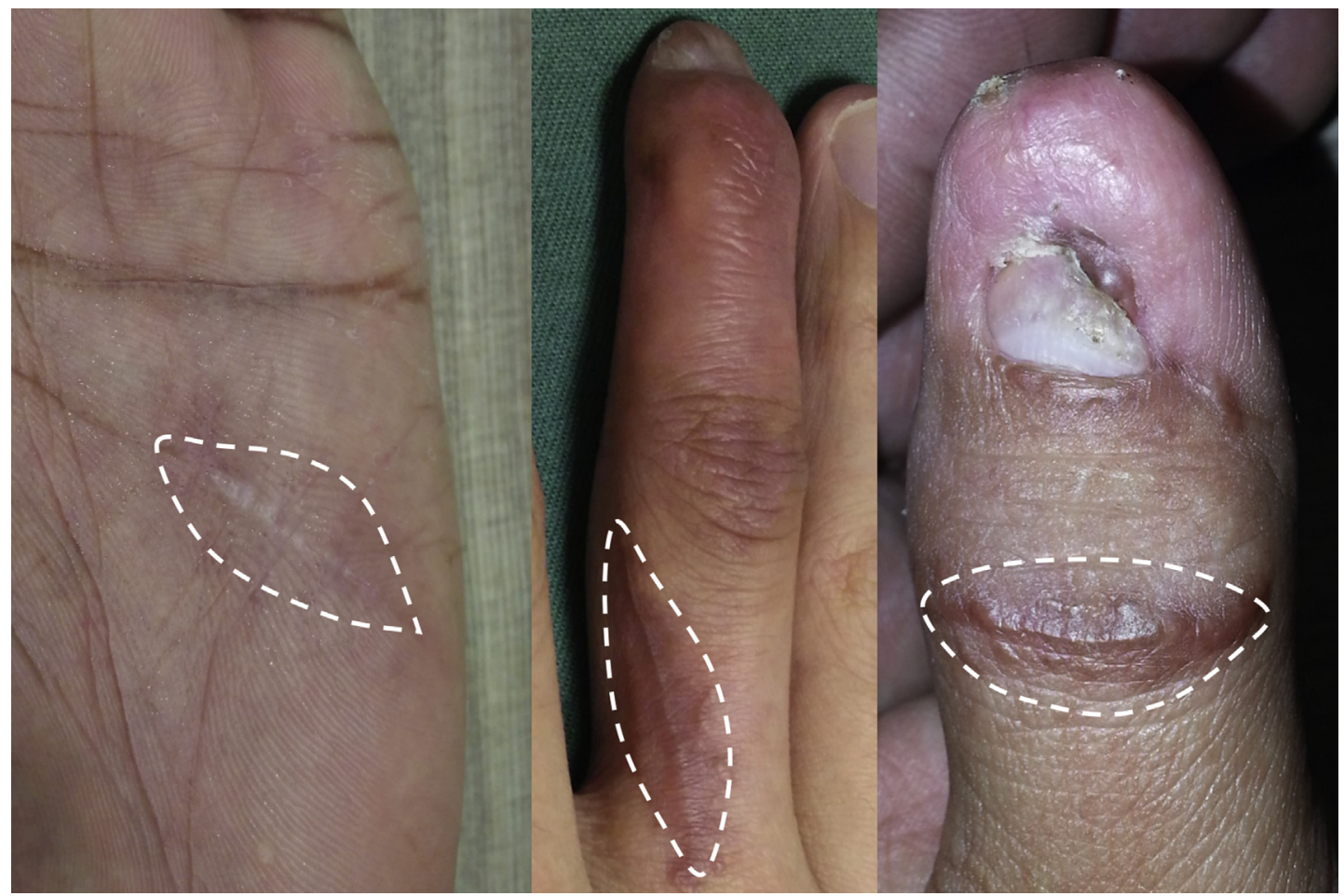

Fig. 6. FTSGs can be harvested from inconspicuous sites such as palmar crease (left), mid axial skin (middle), and dorsal digital crease (right) to optimize the appearance of the hand or digit.

Retrograde flow vascular island flaps ${ }^{30,31}$ provide great flexibility for pulp reconstruction should collateral flow through palmar arches be wellpreserved. The conventional technique requires
FTSG to cover donor site along the mid axis of the proximal phalanx, whereas a modified approach we adopted could obviate the requirement to promote better donor site appearance (Fig. 8).

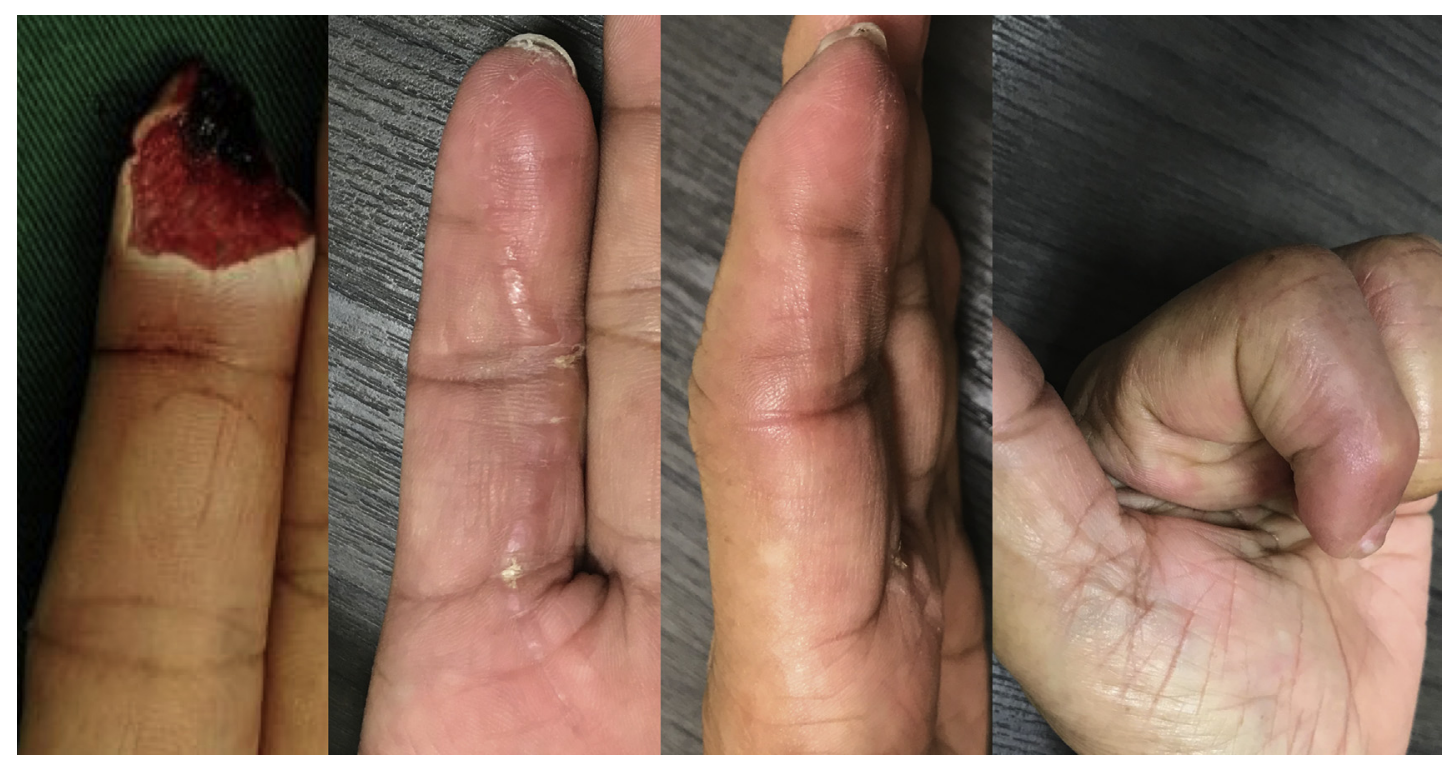

Fig. 7. Pulp loss of the left index finger was reconstructed with an ulnar-based triangular advancement flap to avoid sensitivity along the radial border of the index finger. Finger mobility exercise decreased joint stiffness. 


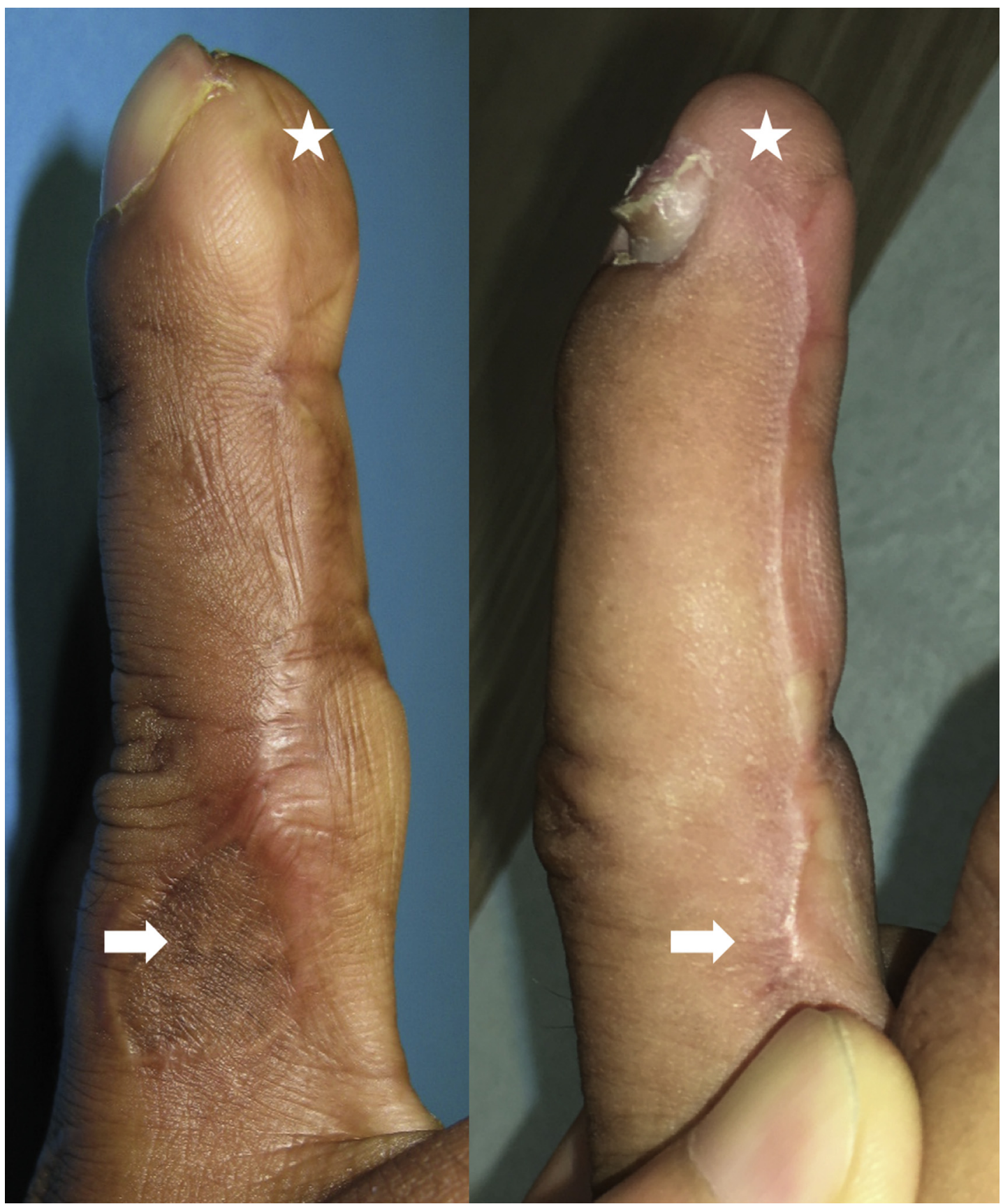

Fig. 8. Flap (star) and donor site (arrow) appearance with conventional (left) and modified (right) approaches, where the donor site was closed primarily rather than skin grafted to provide better appearance.

In our practice, we avoid heterodigital flaps to minimize cortical disorientation and donor site morbidity ${ }^{32-34}$ for digital (eg, thumb) reconstruction. For thumb pulp reconstruction, we prefer either the locoregional flaps ${ }^{33,35-37}$ or free toe pulp transfer. In the long term, there is no significant difference between the sensory perception of innervated and noninnervated flaps. ${ }^{33}$

\section{BONE LOSS}

Bone loss and geometric distortion are concerns in oblique fingertip amputations. To minimize loss of bone support and fingertip length, a vascularized bone graft can be obtained as part of a VY flap $^{38}$ to reconstruct the fingertip while preserving length (Fig. 9). 


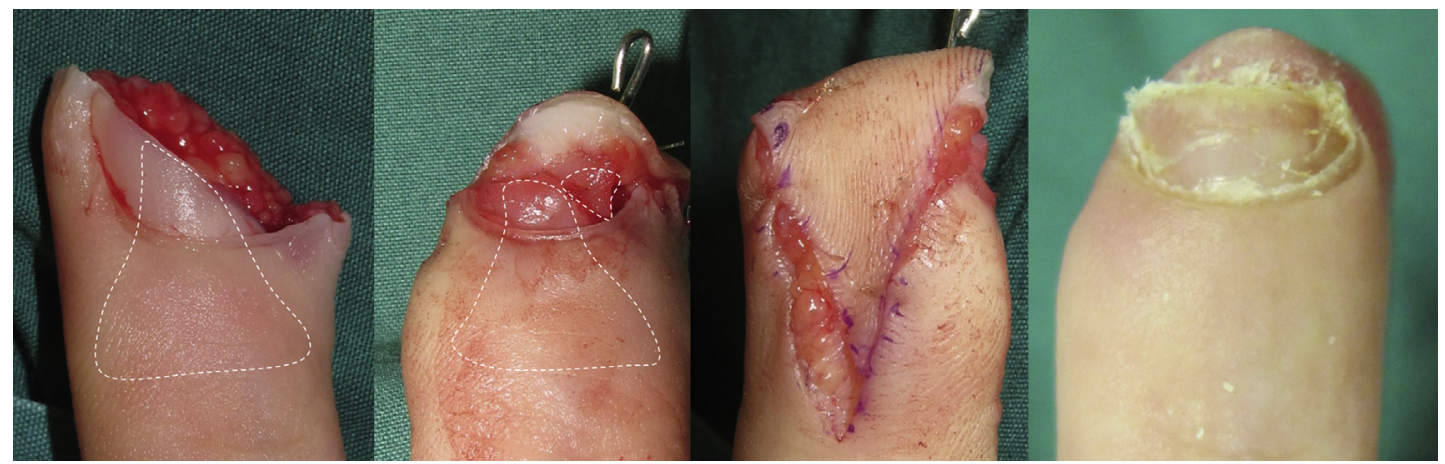

Fig. 9. Oblique amputation reconstructed with a osteocutaneous VY flap to reconstitute the nail complex contour (bone outline in dashed line). Satisfactory nail contour and normal looking fingertip after remodeling.

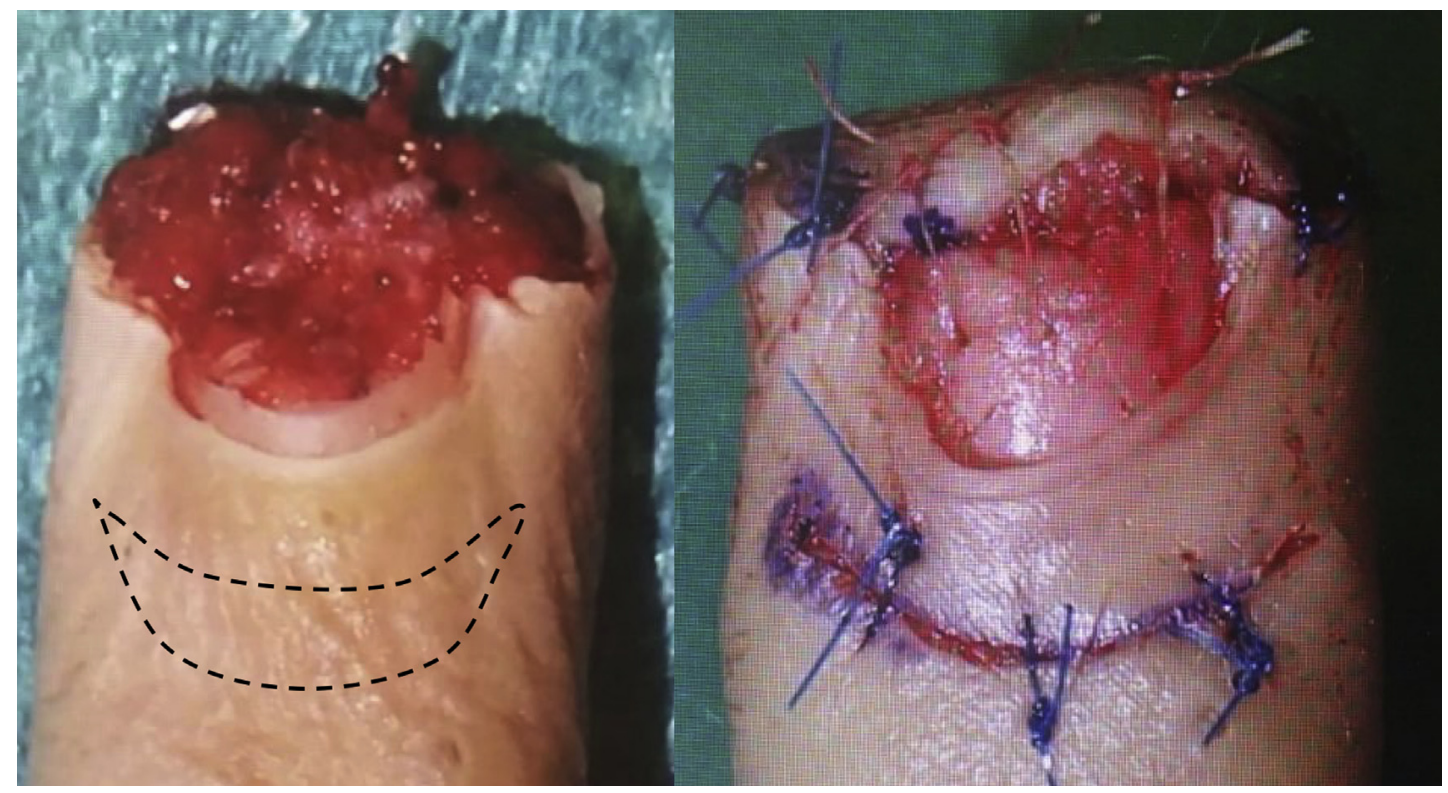

Fig. 10. A very short nail complex can be relatively lengthened by recessing the eponychium. A crescent area of skin is excised (dashed lines) and the eponychium is advanced proximally to expose more matrix.
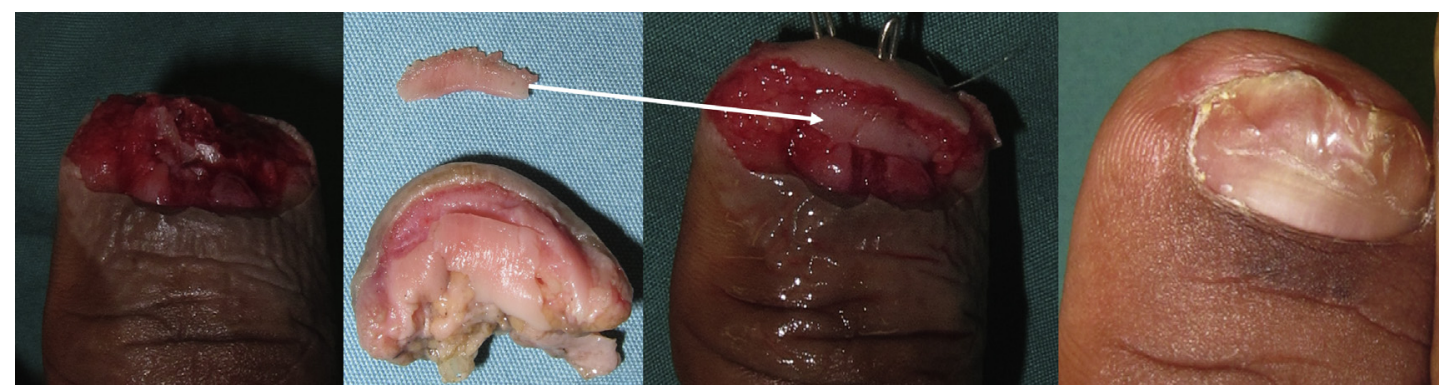

Fig. 11. Amputation injury with bone and matrix loss (left). Matrix graft obtained as spare parts from amputate (middle) replaced over VY advancement flap. Acceptable outcome achieved at 3 months (right). 


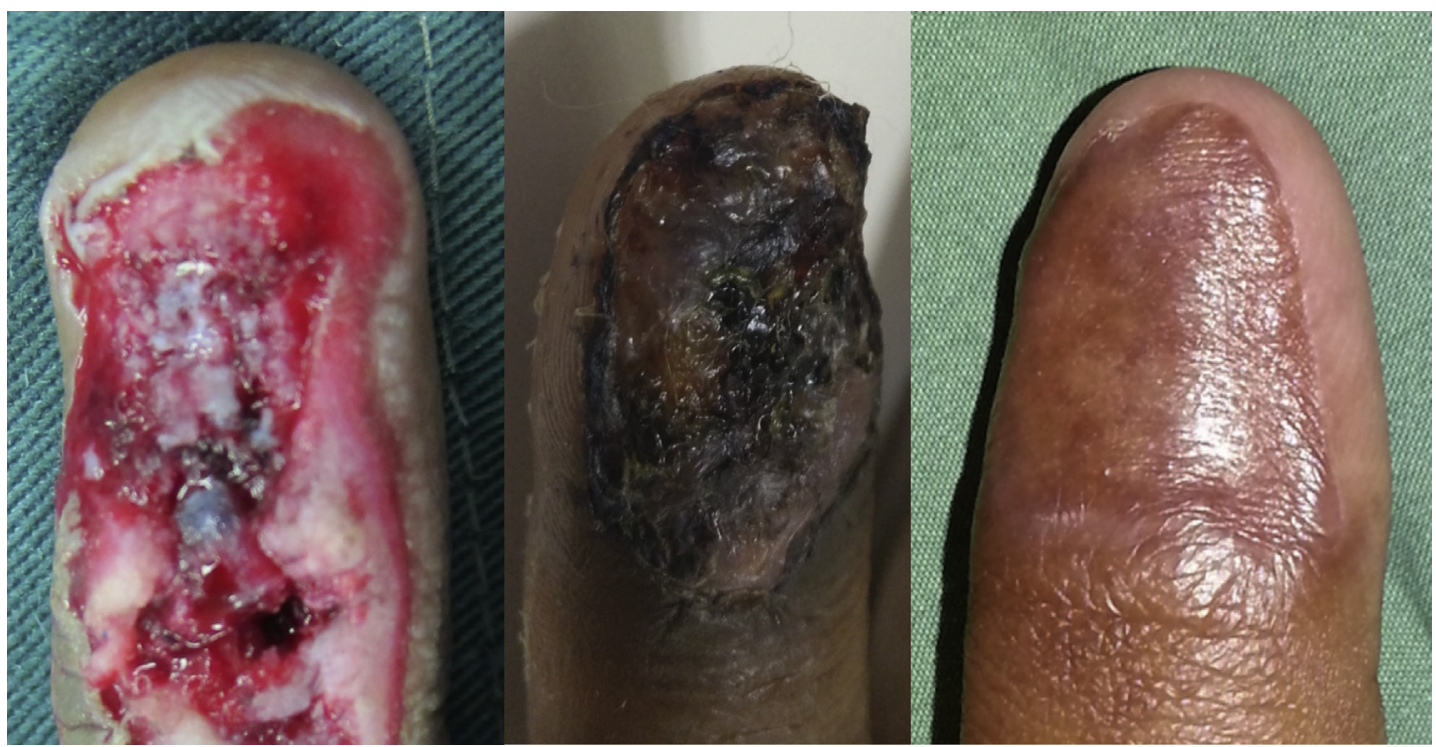

Fig. 12. Dorsal shaving injury resulting in loss of nail matrix (left), replaced by FTSG (intermediate stage, middle) and eventual satisfactory outcome (3 months, right).

\section{Nail Complex Reconstruction}

In situations where residual nail complex is sparse, nailfold recession ${ }^{39}$ could be considered to augment relative length of the nail plate (Fig. 10). Nail matrix graft from an amputated toe (Fig. 11) or a split thickness graft from the toes may be obtained to reconstruct missing matrix. In the complete loss of nail matrix, FTSG may be performed with satisfactory results. Of note is that the direct application of a graft on a bare distal phalanx cortex (Fig. 12) does not compromise graft nutrition. ${ }^{40}$

\section{SUMMARY}

Fingertip injuries affect patients in numerous ways and outcomes are not always predictable. Each encounter calls for a considered evaluation of the functional and aesthetic expectations of patients, tailored to societal and cultural norms. The treatment goal of a pain-free and functional fingertip is weighed against the potential morbidity and expected outcome of the proposed procedure. The healing and remodeling trajectory of bone, pulp tissue, nail matrix, and grafts vary considerably. These variables are to be considered in the formulation of the overall treatment plan for fingertip injuries.

\section{REFERENCES}

1. Mancini F, Chiara F, Ramirez JD, et al. A fovea for pain at the fingertips. Curr Biol 2013;23:496-500.
2. Roux FE, Djidjeli I. Functional architecture of the somatosensory homunculus detected by electrostimulation. J Physiol 2018;596(5):941-56.

3. Hustedt JW, Chung A, Bohl DD, et al. Evaluating the effect of comorbidities on the success, risk, and cost of digital replantation. J Hand Surg Am 2016;41(12): 1145-52.

4. Payatakes AH, Nikolaos P, Fedorcik GG, et al. Current practice of microsurgery by members of the American society for surgery of the hand. J Hand Surg 2007;32A:541-7.

5. Shi Q, Sinden K, M JC, et al. A systematic review of prognostic factors for return to work following workrelated traumatic injury. J Hand Ther 2014;27:55-62.

6. Peacock S, Patel S. Cultural influences on pain. Rev Pain 2008;1(2):6-9.

7. Steinberg F. The law of workers' compensation as it applies to hand injuries. Occup Med 1989;4(3): 559-71.

8. Lee PW, Ho ES, Tsang AK, et al. Psychosocial adjustment of victims of occupational hand injuries. Soc Sci Med 1985;20(5):493-7.

9. Simon RR, Wolgin M. Subungual hematoma: association with occult laceration requiring repair. Am J Emerg Med 1987;5(4):302-4.

10. Seaberg DC, Angelos WJ, Paris PM. Treatment of subungual hematomas with nail trephination: a prospective study. Am J Emerg Med 1991;9(3):209-10.

11. Yamano Y. Replantation of the amputated distal part of the fingers. J Hand Surg Am 1985;10(2):211-8.

12. Dubert $T$, Houimli $S$, Valenti $P$, et al. Very distal finger amputations: replantation or "reposition-flap" repair? J Hand Surg Br 1997;22(3):353-8. 
13. Yam A, Tan SH, Tan AB. A novel method of rapid nail bed repair using 2-octyl cyanoacrylate (Dermabond). Plast Reconstr Surg 2008;121(13):148e-9e.

14. Lee LP. A simple and efficient treatment for fingertip injuries. J Hand Surg Br 1995;20(1):63-71.

15. Butler DP, Murugesan L, Ruston J, et al. The outcomes of digital tip amputation replacement as a composite graft in a paediatric population. J Hand Surg Eur Vol 2016;41(2):164-70.

16. Chen SY, Wang CH, Fu JP, et al. Composite grafting for traumatic fingertip amputation in adults: technique reinforcement and experience in 31 digits. J Trauma 2011;70:148-53.

17. Moynihan FJ. Long-term results of split-skin grafting in finger-tip injuries. Br Med J 1961;2(5255):802-6.

18. Shepard $\mathrm{GH}$. Treatment of nail bed avulsions with split-thickness nail bed grafts. J Hand Surg Am 1983;8(1):49-54.

19. Yong FC, Teoh LC. Nail bed reconstruction with splitthickness nail bed grafts. J Hand Surg Br 1992; 17(2):193-7.

20. Lee JH, Burn JS, Kang SY, et al. Full-thickness skin grafting with de-epithelization of the wound margin for finger defects with bone or tendon exposure. Arch Plast Surg 2015;42:334-40.

21. Tan RE, Ying CTQ, Sean LWH, et al. Well-camouflaged skin graft donor sites in the hand. Tech Hand Up Extrem Surg 2015;19(4):153-6.

22. Germann G, Rudolf KD, Levin SL, et al. Fingertip and thumb tip wounds: changing algorithms for sensation, aesthetics, and function. J Hand Surg Am 2017;42(4):274-84.

23. Atasoy E, loakimidis E, Kasdan ML, et al. Reconstruction of the amputated fingertip with a triangular volar flap. A new surgical procedure. J Bone Joint Surg Am 1970;52:921-6.

24. Tranquilli-Leali E. Ricostruzione dell'apice delle falangi ungueali mediante autoplastica volare peduncolata per scorrimento. Infort Traumatol Lav 1935; 1:186-93.

25. Gurdin M, Pangman WJ. The repair of surface defects of fingers by trans-digital flaps. Plast Reconstr Surg (1946) 1950;5(4):368-71.

26. Foucher G, Khouri RK. Digital reconstruction with island flaps. Clin Plast Surg 1997;24(1):1-32.
27. Rehim SA, Chung KC. Local flaps of the hand. Hand Clin 2014;30(2):137-51.

28. Venkataswami R, Subramanian N. Oblique triangular flap: a new method of repair for oblique amputations of the fingertip and thumb. Plast Reconstr Surg 1980;66(2):296-300.

29. Evans DM, Martin DL. Step-advancement island flap for fingertip reconstruction. Br J Plast Surg 1988; 41(2):105-11.

30. Lai CS, Lin SD, Yang CC. The reverse digital artery flap for fingertip reconstruction. Ann Plast Surg 1989;22(6):495-500.

31. Adani R, Busa R, Pancaldi G, et al. Reverse neurovascular homodigital island flap. Ann Plast Surg 1995;35(1):77-82.

32. Littler JW. The neurovascular pedicle method of distal transposition for reconstruction of the thumb. Plast Reconstr Surg (1946) 1953;12(5):303-19.

33. Woon CY, Lee JY, Teoh LC. Resurfacing hemipulp losses of the thumb: the cross finger flap revisited: indications, technical refinements, outcomes, and long-term neurosensory recovery. Ann Plast Surg 2008;61(4):385-91.

34. Teoh LC, Tay SC, Yong FC, et al. Heterodigical arterialized flaps for large finger wounds: results and indications. Plast Reconstr Surg 2003;111(6): 1905-13.

35. Pho RW. Local composite neurovascular island flap for skin cover in pulp loss of the thumb. J Hand Surg Am 1979;4(1):11-5.

36. Foucher $\mathrm{G}$, Braun JB. A new island flap transfer from the dorsum of the index to the thumb. Plast Reconstr Surg 1979;63(3):344-9.

37. Brunelli F, Vigasio A, Valenti P, et al. Arterial anatomy and clinical application of the dorsoulnar flap of the thumb. J Hand Surg Am 1999;24(4):803-11.

38. Foo TL, Arul M. Osteocutaneous VY flap to preserve length in coronal oblique fingertip amputation. Hand Surg 2013;18(2):297-9.

39. Xing S, SHen Z, Jia W, et al. Aesthetic and functional results from nailfold recession following fingertip amputations. J Hand Surg Am 2015;40(1):1-7.

40. Puhaindran ME, Cordeiro PG, Disa JJ, et al. Fullthickness skin graft after nail complex resection for malignant tumors. Tech Hand Up Extrem Surg 2011;15(2):84-6. 